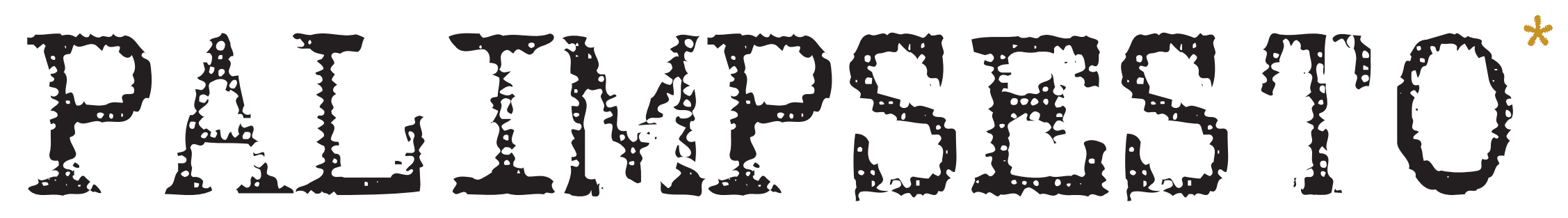

102। Entrevista. Alberto Campo Baeza I Alberto Peñin |

PRIMUS INTER PARES

1051 Efímero. Muebles de patio. Sistema modular de mobiliario efímero I Cito Ballesta y Marta Gómez I

106I Difusión. Josep Maria Sostres. Práctica, reflexión y docencia de arquitectura I Daniel García-Sostres y Berta Bardí i Milà I

08। Crítica. La crítica arquitectónica y la imagen del arquitecto I Rafael Gómez-Moriana I

110I Investigación. Las voces y los ecos. Sobre música y arquitectura I Joaquin Arnau Amo I

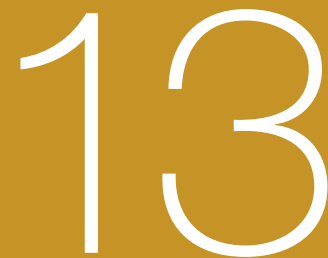

112I Investigación. La estructuración del espacio por la gravedad y la luz a lo largo de la historia I Oscar Linares de la Torre I

117I Investigación. El edificio urbano como gesto cívico I Maria Elia Gutierrez Mozo I

4 EUR

I20। Contra. La manzana y la hoja. De cómo en arquitectura no hay verdades inconclusas I Alberto Campo Baeza ।

Entrevista a
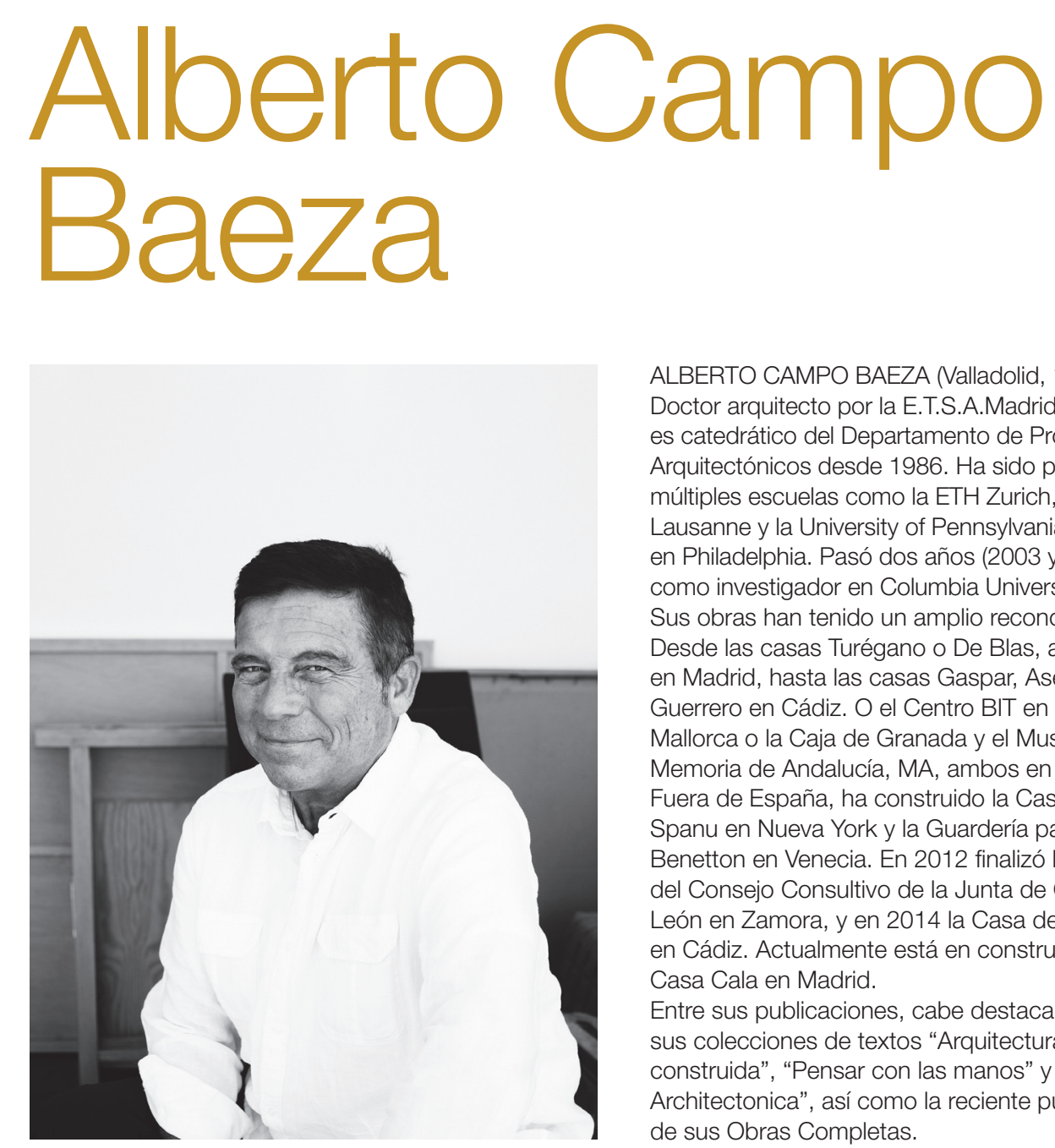

ALBERTO CAMPO BAEZA (Valladolid, 1946) es Doctor arquitecto por la E.T.S.A.Madrid, donde es catedrático del Departamento de Proyectos Arquitectónicos desde 1986. Ha sido profesor en múltiples escuelas como la ETH Zurich, la EPFL Lausanne y la University of Pennsylvania (PENN) en Philadelphia. Pasó dos años (2003 y 2011) como investigador en Columbia University. Sus obras han tenido un amplio reconocimiento. Desde las casas Turégano o De Blas, ambas en Madrid, hasta las casas Gaspar, Asencio y Guerrero en Cádiz. O el Centro BIT en IncaMallorca o la Caja de Granada y el Museo de la Memoria de Andalucía, MA, ambos en Granada. Fuera de España, ha construido la Casa Olnick Spanu en Nueva York y la Guardería para Benetton en Venecia. En 2012 finalizó la Sede del Consejo Consultivo de la Junta de Castilla y León en Zamora, y en 2014 la Casa del Infinito en Cádiz. Actualmente está en construcción la Casa Cala en Madrid.

Entre sus publicaciones, cabe destacar sus colecciones de textos "Arquitectura construida", "Pensar con las manos" y "Principia Architectonica", así como la reciente publicación de sus Obras Completas.

\section{La estructuración del espacio por la gravedad y la luz a lo largo de la historia \\ Oscar Linares de la Torre}

El objetivo de este artículo es señalar la relación existente entre el desarrollo del conocimiento científico sobre la gravedad y la luz desde el ámbito de la física y las estrategias proyectuales destinadas a manipular ambos fenómenos con fines espaciales a lo largo de la historia.

El análisis se articula en base a una interpretación del autor de la teoría de las concepciones espaciales de Sigfried Giedion, según la cual la historia de la arquitectura puede entenderse como una sucesión de distintas maneras de concebir el espacio.

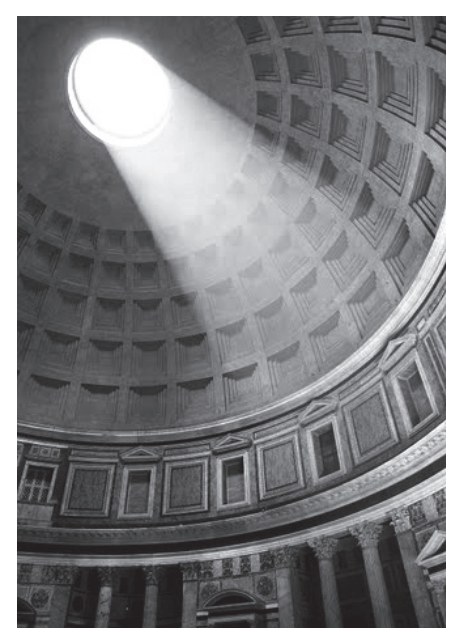

\section{Josep Maria Sostres}

Práctica, reflexión y docencia de arquitectura

Daniel García-Escudero y Berta Bardí i Milà

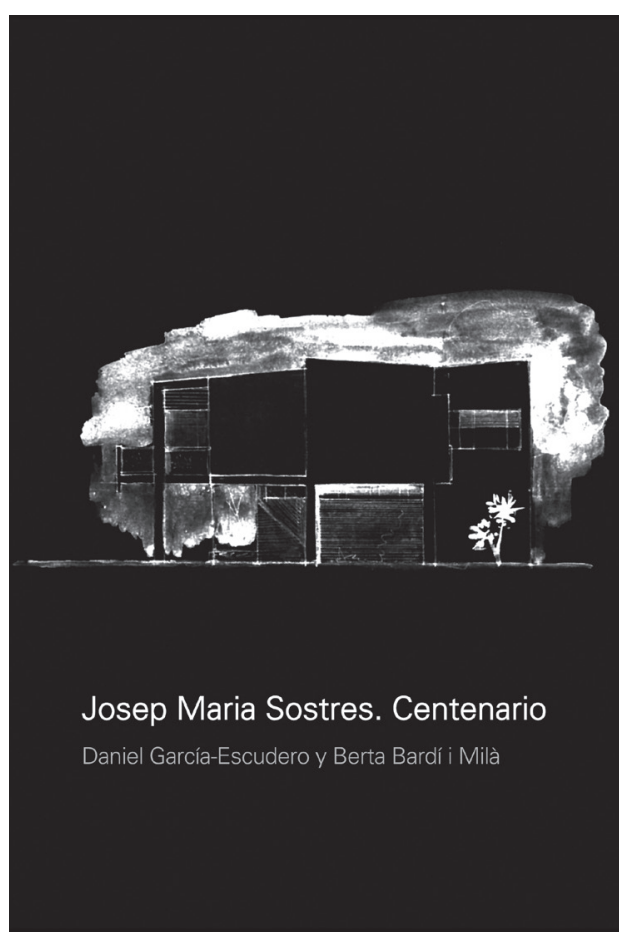

Josep Maria Sostres fue un profesor de historia del arte y la arquitectura, un crítico informado y lúcido, un arquitecto abnegado y cuidadoso. Sus proyectos partían de unos depurados principios de clara vocación didáctica. A partir de esos principios, Sostres hablaba de sus obras con distancia y precisión, convirtiéndolas en herramientas de estudio y aprendizaje, en ejemplos de un conocimiento acumulativo fruto de la tradición moderna.

Con motivo del reciente centenario de su nacimiento, se acaba de publicar el libro Josep Maria Sostres: Centenario, unos estudios críticos en torno a su figura, pensamiento y obra. Desde diversos ángulos, el libro pretende colaborar en la construcción de un conocimiento más completo de un arquitecto que hoy en día continúa siendo marginal. 